06

\title{
Псевдощель, нанокристаллы и электропроводность легированного силикатного стекла
}

\author{
( Г. Абдурахманов, ${ }^{1,2}$ В.И. Шиманский, ${ }^{3}$ Б.Л. Оксенгендлер, ${ }^{2}$ Б.Е. Умирзаков, ${ }^{1}$ А.Н. Уроков ${ }^{1}$ \\ ${ }^{1}$ Ташкентский государственный технический университет, \\ 100095 Ташкент, Узбекистан \\ ${ }^{2}$ Национальный университет Узбекистана, \\ 100174 Ташкент, Узбекистан \\ ${ }^{3}$ Белорусский государственный университет, \\ 220030 Минск, Белоруссия \\ e-mail: fyashjon@gmail.com, gulmirzo@mail.ru
}

Поступило в Редакцию 12 мая 2020 г.

В окончательной редакции 8 августа 2020 г.

Принято к публикации 1 сентября 2020 г.

Представление о псевдощели и нанокристаллах использовано для объяснения механизма электропроводности силикатного стекла, легированного оксидами переходных металлов (толстопленочные резисторы). Псевдощель возникает между потолком валентной зоны стекла и примесной зоной, созданной диффузией атомов лигатуры в стекло при спекании. Нанокристаллы образуются в стекле в процессе его варки, претерпевают структурные превращения при высоких температурах и действуют как центры локализации носителей заряда. Достигнуто качественное соответствие модели с экспериментальной температурной зависимостью проводимости легированного стекла в интервале от гелиевых температур до $1100 \mathrm{~K}$.

Ключевые слова: силикатное стекло, толстопленочные резисторы, легирование, туннелирование, нанокристаллы, псевдощель.

DOI: 10.21883/JTF.2021.02.50363.165-20

\section{Введение}

Силикатное стекло, легированное оксидами переходных металлов (ЛСС), широко известно как толстопленочный (или чип-) резистор [1], массово применяемый в электронной аппаратуре, используется также как функциональный материал в датчиках различных воздействий (физических и химических). Поэтому механизм электропроводности ЛСС и влияние на нее различных факторов исследуются во многих лабораториях [2-4].

ЛСС получают спеканием смеси порошков стекла (размеры частиц $0.1-0.2 \mu \mathrm{m}$ ) и лигатуры (размеры частиц $0.2-0.5 \mu \mathrm{m})$ - чаще всего $\mathrm{RuO}_{2}$, рутенаты висмута и свинца. Типичная температура спекания $T_{f}=1123 \mathrm{~K}$, продолжительность $\tau_{f}=600 \mathrm{~s}$ для получения толстопленочных резисторов, но условия могут меняться в зависимости от требований к ЛСС и его составу. Электронная микроскопия (рис. 1) и рентгеновская дифракция (рис. 2) показывают, что ЛСС является сильнонеоднородной средой, состоящей из стеклянной матрицы с закрепленными в ней кристаллическими остатками частиц лигатуры. Используемые в ЛСС оксиды или оксидные соединения имеют высокую электропроводность $\left(\rho_{d}=4 \cdot 10^{-7}-10^{6} \Omega \cdot \mathrm{m}\right)$ по сравнению с исходным стеклом $\left(\rho_{g} \geq 10^{14} \Omega \cdot \mathrm{m}\right)$. Поэтому они принимались за центры локализации носителей заряда, и считалось, что носители переходят от одной частицы к другой прыжками с переменной длиной (моттовский механизм) или квантово-механическим туннелированием через тонкий слой стекла. Другим вариантом была теория протекания по электропроводящим цепочкам из соприкасающихся частиц лигатуры.

ЛСС является уникальным электронно-проводящим материалом [5-16], в котором при изменении температуры от гелиевых до $1200 \mathrm{~K}$ последовательно реализуются несколько режимов электропроводности (рис. 3). В известной нам литературе [1-4] (а также в других работах, приведенных там) экспериментально и теоретически исследованы только участки I и II. Интерес к участку II обусловлен условиями применения в радиоэлектронной аппаратуре, к участку I - поисками подтверждения механизмов проводимости, основанных на туннелировании электронов между частицами лигатуры или на прыжках с переменной длиной между ними же. Другим вариантом была теория протекания по электропроводящим цепочкам соприкасающихся частиц лигатуры, несмотря на то, что оценки приводили к среднему расстоянию в $0.5-2.5 \mu \mathrm{m}$ между ними (рис. 4):

$$
L=d \sqrt[3]{\frac{\pi}{6 C}}=d \sqrt[3]{\frac{\pi}{6}\left[1+\frac{\gamma_{d}}{\gamma_{g}}\left(\frac{1}{C_{m}}-1\right)\right]},
$$

где $d-$ средний диаметр частиц лигатуры, $\gamma_{d}$ и $\gamma_{g}-$ плотность лигатуры и стекла соответственно. Такие расстояния исключают непосредственные контакты этих частиц или туннелирование (прыжки) электронов между ними.

Однако вопрос о происхождении минимума на рис. 3 оставался открытым во всех этих моделях. При этом 


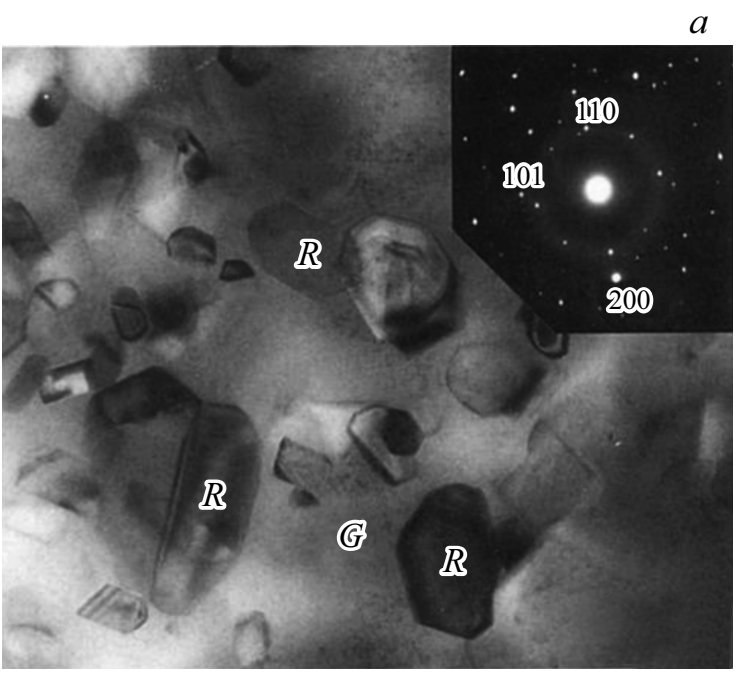

$100 \mathrm{~nm}$

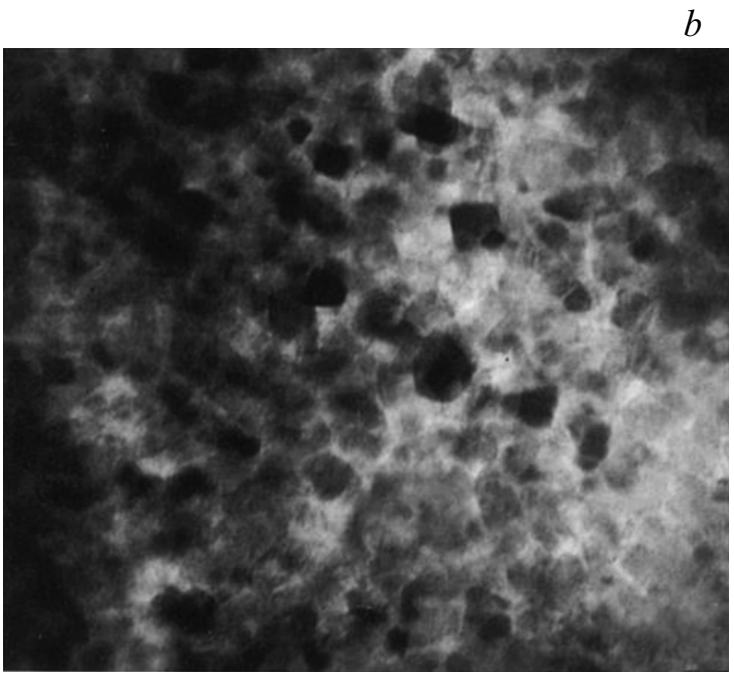

$20 \mathrm{~nm}$

Рис. 1. Структура ЛСС в наномасштабе: $a$ - из пасты Heraeus $8241, R-$ зерна $\mathrm{RuO}_{2}, G-$ стекло. Во вставке - электронная дифракция от выбранного зерна $\mathrm{RuO}_{2} ; b-$ из пасты DuPont 8041. Электронная микрофотография на просвет [17].

выяснилось также, что порог протекания на зависимости проводимости ЛСС от уровня легирования (объемной $C$

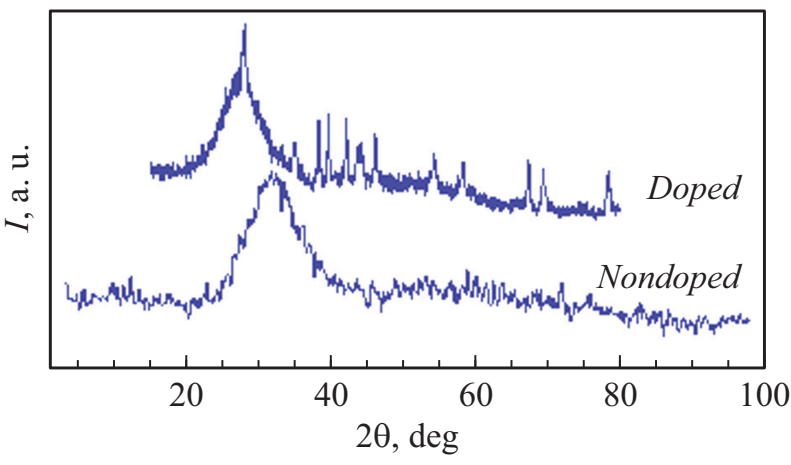

Рис. 2. Рентгенограммы стекла $33 \mathrm{SiO}_{2}+63 \mathrm{PbO}+4 \mathrm{Al}_{2} \mathrm{O}_{3}$ (шихта, по массе) до легирования и после легирования (10 wt.\% $\mathrm{RuO}_{2}$ ). Кристаллические рефлексы в картине для легированного стекла принадлежат $\mathrm{RuO}_{2}$ [18].

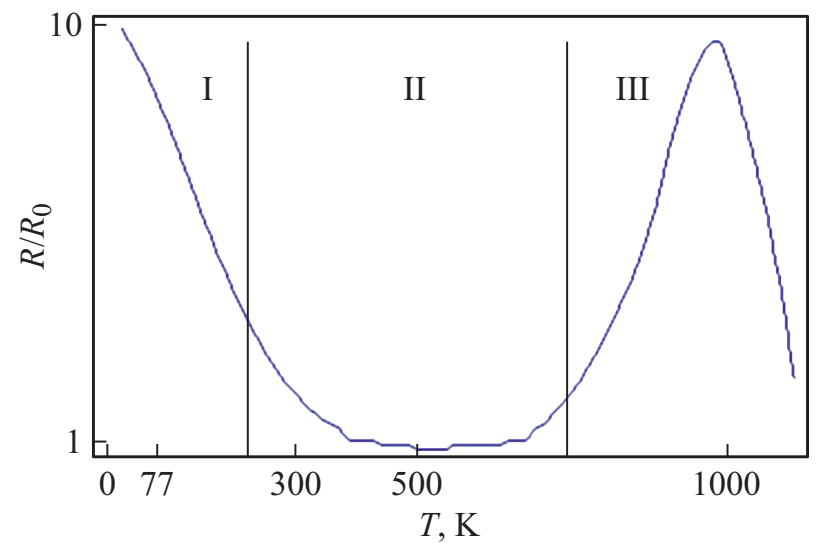

Рис. 3. Температурная зависимость сопротивления ЛСС (схематично).

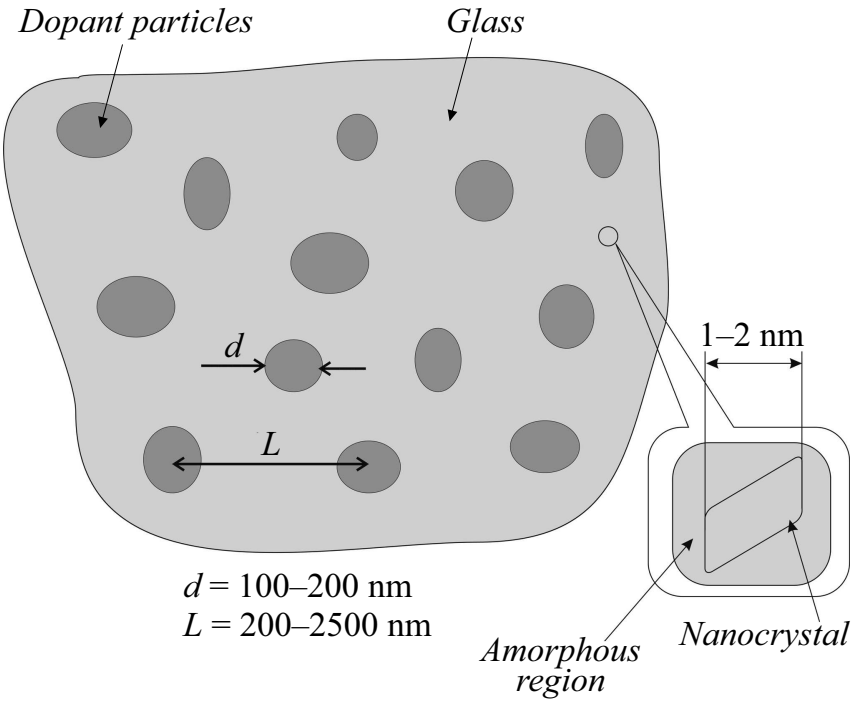

Pис. 4. Структура ЛСС в микро- и наномасштабах.

или массовой $C_{m}$ доли лигатуры) существенно ниже $(1-5 \mathrm{vol} . \%)$, чем следует из теории $\left(C_{\mathrm{cr}}=16 \mathrm{vol} . \%\right)$, или вовсе исчезает в зависимости от состава ЛСС и условий спекания [18]. Критический индекс $t$ теории протекания $\rho(C)=A\left(C-C_{\mathrm{cr}}\right)^{t}$ в ЛСС также существенно отличается от теоретического значения $(t=2.5-5$ против 1.7$)$.

Как показал Г. Абдурахманов и соавторы $[19,20]$, причина такого расхождения эксперимента и теории заключалась в том, что исследователи не принимали во внимание возможное взаимодействие частиц лигатуры и стекла при спекании и его влияние на электропроводность ЛСС, хотя Adachi et.al. [21] показали, что в стекле растворяется до 7 at.\% двуокиси рутения, причем 
длина диффузии превышает $1 \mu \mathrm{m}$. A Morten с соавт. [22] установили, что в ЛСС при спекании идет обменная реакция между лигатурой и стеклом с частичным переходом свинцовых пирохлоров в рутениевые пирохлоры, вследствие чего электропроводность ЛСС снижается. Но результаты $[21,22]$ не были развиты дальше.

Диффузия атомов лигатуры в стекло при спекании как причина наблюдаемых снижения или отсутствия порога протекания, зависимости проводимости ЛСС от $T_{f}$ и $\tau_{f}$ была обоснована в [20]. Оказалось, что в типичных условиях спекания диффузионная длина атомов лигатуры $\left(l_{d} \geq 30 \mu \mathrm{m}\right.$ для состава, указанного на рис. 2) превышает среднее расстояние между частицами лигатуры, т.е. диффузионные зоны вокруг частиц лигатуры сильно перекрываются, превращая стекло в сплошной электропроводящий материал. Развитие этого подхода позволило объяснить влияние размеров частиц лигатуры на проводимость ЛСС [20]. Предположение о существовании в стекле нанокристаллов силикатов с размерами в $1-2 \mathrm{~nm}$ и возможности структурных переходов в них вместе с образованием примесной зоны из-за диффузии атомов лигатуры было использовано в [23] для объяснения резкого роста сопротивления ЛСС (участок III на рис. 3), впервые обнаруженного одним из авторов настоящей работы [24].

Сочетание нанокристаллов и примесной зоны с электрон-фононной связью (влияющей на положение примесной зоны [25-29]) дало объяснение минимуму $\rho(T)$ и последующей за ним в низкоомных ЛСС „металлической“ проводимости $\rho \propto T^{\alpha}, \alpha=1-2$ [5]. Было установлено $[5,18]$, что последняя является следствием слияния примесной зоны с валентной зоной стекла, когда основной причиной температурной зависимости проводимости ЛСС становится рассеяние носителей на ионах, фононах и друг на друге.

Но в работах $[19,20]$ при рассмотрении диффузии атомов лигатуры в стекло считалось, что процесс изотропный, а стекло - однородное (не учитывалось возможное влияние нанокристаллов на диффузию атомов лигатуры). В действительности же сильная неоднородность ЛСС (рис. 1,2) может привести к тому, что в нем классические законы диффузии могут претерпевать существенные изменения [30], а отсутствие дальнего порядка создает протяженные „хвосты“ плотности состояний электронов [31] в примесной зоне и у края валентной зоны стекла. Возможное перекрытие последних создает псевдощель в распределении плотности состояний электронов.

В настоящей работе мы попытались, опираясь на анализ опубликованных результатов исследования механизмов электропроводности ЛСС, основываясь на существовании нанокристаллов и на представлении об образовании псевдощели, описать некоторые особенности электропроводности ЛСС, не зависящие от конкретного состава последнего.

\section{1. Нанокристаллы силикатов в стекле и диффузия атомов лигатуры}

Нанокристаллы с размерами 1-2 nm (рис. 2, формула Шерера) возникают в остывающем стекле самопроизвольно и, следовательно, являются для системы энергетически выгодными. Другими словами, нанокристаллы являются потенциальными ямами. Медленность кристаллизации стекла, а также близость состава нанокристаллов и остальной массы стекла указывают на малую глубину ям. Эти потенциальные ямы служат центрами локализации носителей заряда, и по ним осуществляется прыжковая проводимость, но их глубина пока не оценена.

С другой стороны, нанокристаллы имеют повышенную плотность упаковки атомов по сравнению с неупо-

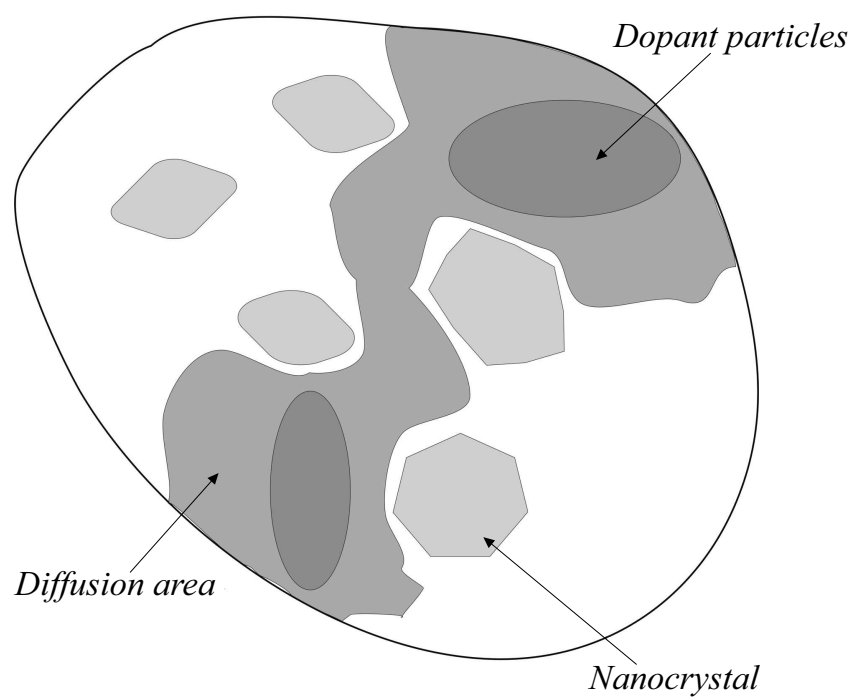

Рис. 5. Диффузионные зоны в ЛСС.

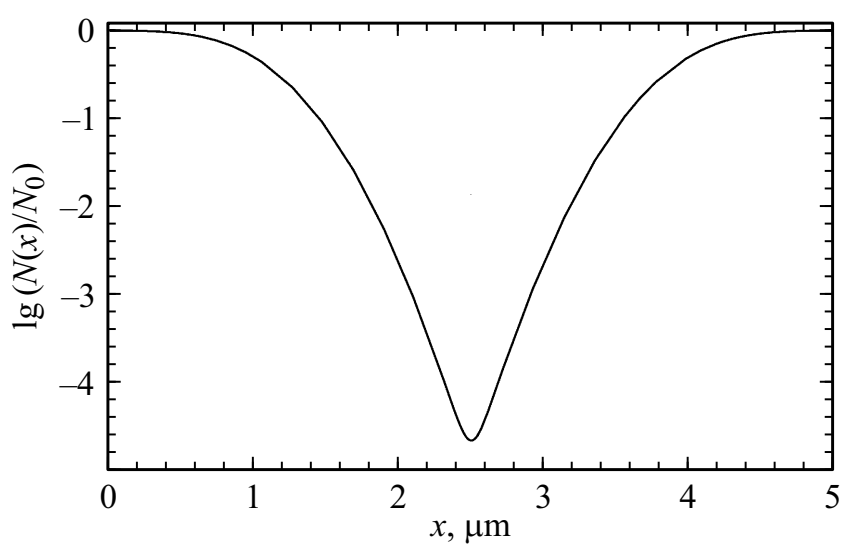

Рис. 6. Распределение атомов лигатуры между частицами. $L=5 \mu \mathrm{m}$ (см. рис. 4). Моделирование по уравнению Фика для двух источников диффузии [20]. Это распределение показывает образование псевдощели в запрещенной зоне стекла вблизи потолка его валентной зоны. 
рядоченной частью стекла, что снижает коэффициент диффузии атомов лигатуры в них при спекании. Поэтому концентрация атомов лигатуры в нанокристаллах будет ниже, чем в стеклянных прослойках между ними. Таким образом, в ЛСС мы имеем показанную на рис. 5 и 6 картину распределения атомов лигатуры и электропроводности (в предположении, что электропроводность ЛСС пропорциональна концентрации атомов лигатуры в стекле).

Таким образом, наличие нанокристаллов в стекле усложняет не только структуру ЛСС, но создает дополнительную неоднородность в распределении его электропроводности.

\section{2. Псевдощель и электропроводность ЛСС}

Диффузия атомов лигатуры в стекло при спекании создает примесную зону в запрещенной зоне стекла [23] аналогично диффузионному легированию полупроводников. Поскольку знак термоЭДС в ЛСС положительный [6], эта примесная зона расположена вблизи потолка валентной зоны стекла (дырочная проводимость). Оказалось также, что знак термоЭДС в ЛСС положительный даже тогда, когда лигатура имеет отрицательный знак термоЭДС. Однако параметры примесной зоны в ЛСС другими авторами не рассматривались.

Оценим теперь параметры примесной зоны в ЛСС, основываясь на известных особенностях ЛСС и при некоторых предположениях.

Такими особенностями ЛСС являются [6] крайне низкий коэффициент Холла (ЭДС Холла не поддается измерению) и отсутствие фотопроводимости, что свидетельствует о высокой концентрации свободных носителей заряда (дырок), об их малой длине свободного пробега, а также о полной ионизации примесных атомов. Оцененная по уровню шумов верхняя граница подвижности дырок составляет менее $5 \cdot 10^{3} \mathrm{~cm}^{2} \cdot \mathrm{V}^{-1} \cdot \mathrm{s}^{-1}$ для образцов с $\rho=200 \Omega \cdot \mathrm{cm}$, и возрастает до $3 \cdot 10^{2} \mathrm{~cm}^{2} \cdot \mathrm{V}^{-1} \cdot \mathrm{s}^{-1}$ для образцов с $\rho=0.2 \Omega \cdot \mathrm{cm}$. Концентрация $p$ дырок для этих образцов оценена как $p>8.3 \cdot 10^{18} \mathrm{~cm}^{-3}$ и $p>1.4 \cdot 10^{21} \mathrm{~cm}^{-3}$ соответственно.

Из этих данных в предположении, что длина свободного пробега носителей не менее нескольких ангстрем, нами была оценена эффективная масса $m^{*}$ дырок: $m^{*} \geq 330 m_{0}$ ( $m_{0}$ - масса свободного электрона), т. е. ЛСС является системой с тяжелыми фермионами.

Выше говорилось, что в низкоомных ЛСС вблизи комнатной температуры после минимума $\rho(T)$ наступает „металлическая“ проводимость вследствие слияния примесной зоны с валентной зоной стекла. Температурный коэффициент ширины зоны составляет $(2-5) \cdot 10^{-4} \mathrm{eV} / \mathrm{K}[25-29]$. Поэтому щель между примесной зоной и потолком валентной зоны при $T=0 \mathrm{~K}$ имеет ширину $60-150 \mathrm{meV}$.

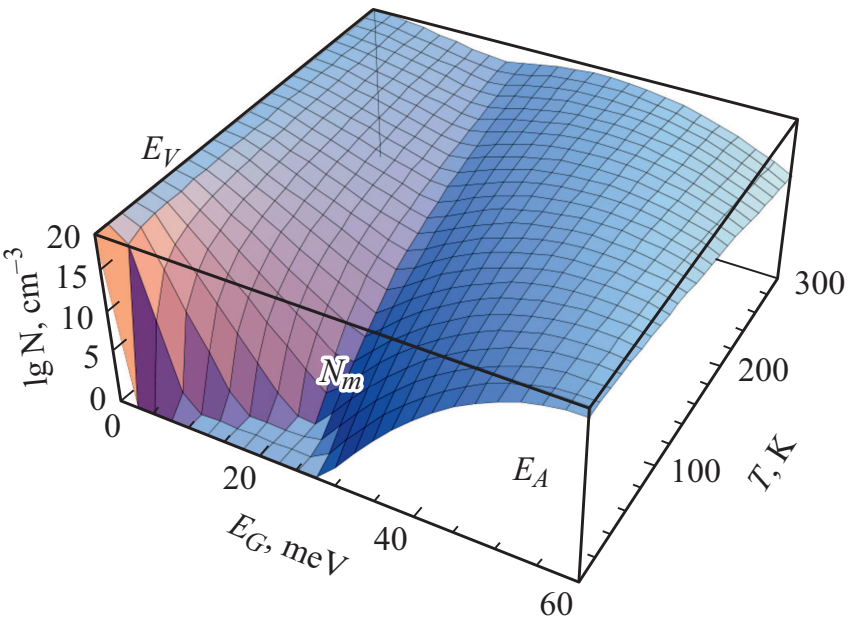

Рис. 7. Эволюция псевдощели $E_{G}$ и минимальной плотности состояний $N_{m}$ в ней с ростом температуры. $E_{V}$ и $E_{A}-$ валентная и примесная зоны соответственно.

Ширину самой примесной зоны можно оценить по эффективной массе дырок [32]

$$
m^{*}=\hbar^{2} /\left(J a_{0}^{2}\right),
$$

где $\hbar-$ постоянная Планка, $a_{0}$ - постоянная решетки (в случае оксидных стекол ее можно принять примерно равной среднему расстоянию между катионами). Оценка ширины примесной зоны по этой формуле с $m^{*}=3.3 \cdot 10^{2} m_{0}$, определенной выше, дает $J=23 \mathrm{meV}$.

Необходимо отметить, что ЛСС даже в толстопленочном исполнении (толщина пленки около $25 \mu \mathrm{m}$ ) является объемным материалом, поскольку характерные длины (диффузии или свободного пробега электронов), оцененные по верхней границе подвижности $\left(5 \cdot 10^{-3} \mathrm{~cm}^{2} / \mathrm{V} \cdot \mathrm{s}[6]\right)$, составляют менее $0.1 \mu \mathrm{m}$.

Плотность состояний $N_{A}$ в примесной зоне также связана с эффективной массой носителей:

$$
N_{A}=2 J^{-1}\left[\frac{2 \pi m^{*} k T}{h^{2}}\right]^{3 / 2)} \approx 1.2 \cdot 10^{22} \mathrm{eV}^{-1} \cdot \mathrm{cm}^{-3} \text {. }
$$

Однако щель между примесной зоной и валентной зоной стекла не пустая (псевдощель), поскольку плотность состояний в примесной зоне имеет гауссово распределение и подвержена тепловому размытию (порядка $k T$ ). Предложен ряд механизмов формирования псевдощели в неупорядоченных средах [31]. В случае ЛСС имеет смысл говорить о минимальной плотности состояний $N_{m}$ в псевдощели и ее изменении с температурой (рис. 7) с учетом: а) теплового размытия края валентной зоны стекла $E_{V}$ и примесной зоны $E_{A} ;$ б) сдвига примесной зоны $E_{A}$ к валентной зоне стекла из-за электрон-фононной связи. Для удобства отображения плотность состояний в валентной зоне и примесной зоне приняты примерно одинаковыми, в действительности они отличаются примерно на 2 порядка. 


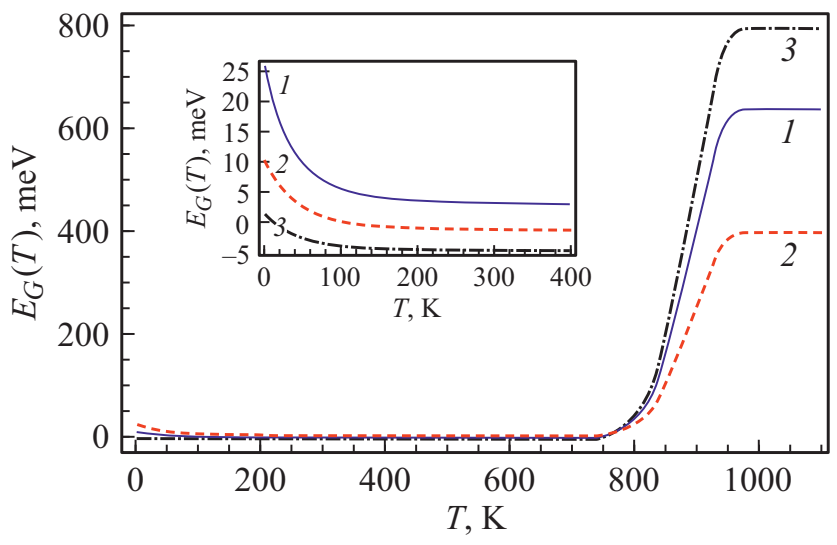

Рис. 8. Динамика ширины псевдощели $E_{G}(T)=E_{V}-E_{\mathrm{I}} .1-3-$ стекла разных составов. Во врезке низкотемпературная часть показана в увеличенном масштабе [5,18].

Как видно из рис. 7, в вышеприведенных условиях минимальная плотность состояний $N_{m}$ в щели между примесной и валентной зонами становится заметной уже при температуре выше $50 \mathrm{~K}$, а при $300 \mathrm{~K}$ она сравнима с плотностью состояний $N_{A}$ в самой примесной зоне. Другими словами, уже при $T \geq 50 \mathrm{~K}$ валентная зона стекла и примесная зона начинают сливаться (зачатки „металлической“ проводимости). С ростом температуры эта тенденция усиливается.

Соответственно электропроводность ЛСС при низких температурах является суммой термоактивационной проводимости по примесной зоне и прыжковой по нанокристаллам:

$$
\begin{aligned}
& \sigma(T)=\sigma_{a}+\sigma_{h}=\sigma_{0} T^{0.5} \exp \left[-\frac{1}{k T}\left(E_{G 0}-\xi\langle\hbar \omega\rangle\right.\right. \\
& \left.\left.\times\left(\operatorname{cth} \frac{\langle\hbar \omega\rangle}{2 k T}-1\right)\right)\right]+\sigma_{1} T^{0.5} \exp \left[-\left(T_{0} / T\right)^{0.25}\right] .
\end{aligned}
$$

Первая экспонента здесь описывает сдвиг примесной зоны из-за электрон-фононной связи [29], а вторая прыжки с переменной длиной [31].

Повышение температуры до $700 \mathrm{~K}$ приводит к тому, что в нанокристаллах силикатов, образовавшихся в стекле при охлаждении после варки и после спекания, начинаются структурные превращения (см., например, [33]), которые в отличие от объемных кристаллических образцов растянуты по температуре из-за разброса связей атомов в неупорядоченной прослойке вокруг этих нанокристаллов. Поскольку высокотемпературные модификации силикатов имеют большее межатомное расстояние, перекрытие волновых функций примесных атомов уменьшается и соответственно снижается электропроводность ЛСС (участок III на рис. 3). При этом тепловое размытие края валентной зоны и самой примесной зоны возрастает, однако оно уже не играет существенной роли из-за того, что расстояние между ними в 10-20 раз превышает исходную ширину щели. Это означает, что в щели минимальная плотность состояний уже практически нулевая. Поведение псевдощели в этой области показано на рис. 8 для тех же условий, что и на рис. 7. Как показали наши эксперименты, после завершения структурных переходов (после максимума на рис. $3, T>1000 \mathrm{~K}$ ) ширина щели между валентной и примесной зонами возрастает до $0.5-1.5 \mathrm{eV}$ (само стекло состава $2 \mathrm{SiO}_{2} \cdot \mathrm{PbO}$ имеет ширину запрещенной зоны $3.3 \mathrm{eV} \mathrm{[34]),} \mathrm{и} \mathrm{ЛСС} \mathrm{проявляет} \mathrm{активационную}$ проводимость с указанной энергией активации (полупроводник).

\section{Заключение}

В ЛСС во всем диапазоне исследованных температур действуют одновременно два механизма электропроводности - прыжковая по нанокристаллам и активационная по примесной зоне, образованной диффузией атомов лигатуры в стекло. При $T=0 \mathrm{~K}$ щель между примесной зоной и валентной зоной стекла не содержит доступных состояний для дырок. На положение примесной зоны влияет электрон-фононная связь, вследствие чего примесная зона с ростом температуры приближается к потолку валентной зоны стекла, их хвосты начинают перекрываться, проводимость ЛСС растет. При некоторой температуре (обычно вблизи комнатной) эти зоны сливаются, создавая „металлическую“ проводимость (концентрация носителей перестает меняться, прыжки не эффективны).

При повышении температуры до $700 \mathrm{~K}$ начинаются структурные превращения в нанокристаллах силикатов, объем ЛСС возрастает, и перекрытие волновых функций атомов примеси убывает, что приводит к отщеплению примесной зоны от валентной зоны стекла и снижению электропроводности ЛСС. После завершения структурных переходов $(T \geq 1000 \mathrm{~K})$ примесная зона фиксируется в новом положении (на расстоянии $0.5-1.5 \mathrm{eV}$ от потолка валентной зоны), и ЛСС превращается в полупроводник с указанной энергией активации проводимости. Теперь уже температурное размытие краев зон и прыжки носителей по нанокристаллам не оказывают заметного влияния на проводимость ЛСС.

\section{Финансирование работы}

Работа выполнена в рамках совместных белорусскоузбекских научно-технических грантов: MRB-OT-201928 Министерства инновационного развития Узбекистана и Ф19УЗБГ-013 Министерство образования Республики Беларусь.

\section{Конфоликт интересов}

Авторы заявляют, что у них нет конфликта интересов. 


\section{Список литературы}

[1] Printed Films, ed. by M. Prudenziati, J. Hormadaly (Woodhead Publishing, Cambridge, 2012)

[2] K.S.R.C. Murthy. Int. J. Adv. Res., 7 (4), 238 (2019). DOI: 10.21474/IJAR01/8811

[3] S. Bindu, M.S. Suresh. British J. Appl. Sci. Technol., 6 (4), 342 (2015). BJAST.2015.093

[4] Ming Wen. Sensors and Actuators A: Physical, A 301, 111779 (2020). https://doi.org/10.1016/j.sna.2019.111779

[5] G. Abdurakhmanov. World J. Cond. Matter Phys., 4 (3), 166 (2014). http://dx.doi.org/10.4236/wjcmp.2014.43021.

[6] G.E. Pike, C.H. Seager. J. Appl. Phys., 48 (12), 5152 (1977).

[7] D.P.H. Smith, J.C. Anderson. Thin Solid Films, 71, 79 (1980).

[8] K. Flachbart, V. Pavlík, N. Tomašovičová, C.J. Adkins, M. Somora, J. Leib, G. Eska. Phys. Stat. Solidi (b), 205, 399 (1998).

[9] W. Schoepe. Physica B: Phys. Condens. Matter., 165\&166, 299 (1990).

[10] F. Johnson, G.M. Crosbie, W.T. Donlon. J. Mater. Sci.: Mat. In Electron., 8 (1), 29 (1997).

[11] J.M. Himelick. Conduction Mechanisms in Thick Film Resistors. PhD Thesis (Purdue: Purdue University, 1980) https://docs.lib.purdue.edu/dissertations/AAI8027287/

[12] Y. Zheng, J. Atkinson, R. Sion. J. Phys. D: Appl. Phys., 36, 1153 (2003). DOI https://doi.org/10.1088/0022-3727/36/9/314

[13] C. Grimaldi. Ch. 5 in: Printed Films ed. by M. Prudenziati, J. Hormadaly (Woodhead Publishing, Cambridge, 2012).

[14] M. Moroz. in: IMAPS SoCal'15 Technical Symposium (Santa Ana, CA, USA, 2015) http://publicationslist.org/data/M45897/ ref-21/Thick Film Systems for Challenging Applications Michail Moroz.pdf

[15] Kenji Adachi, Hiroko Kuno. J. American Ceram. Society, 83 (10), 2441 (2000). https://doi.org/10.1111/j.1151-2916.2000.tb01574.x

[16] D.W. Hammer, J.V. Biggers. Thick Film Hybrid Microcircuit Technology (Wiley Interscience, NY., 1972)

[17] M. Hrovat, G. Dražič, J. Holc, D. Belavič. J. Mater. Sci. Lett., 14, 1048 (1995).

[18] Г. Абдурахманов. Особенности структуры и транспортных свойств бесщелочных свинцовосиликатных стекол, легированных оксидами металлов. Дисс. доктора физ.-мат. наук. (Ташкент, Институт ядерной физики. 2014)

[19] Г. Абдурахманов, Г.С. Вахидова. ЖТФ, 65 (7), 187 (1995).

[20] G. Abdurakhmanov. World J. Cond. Matter. Phys., 1 (2), 19 (2011). DOI: 10.4236/wjemp.2011.12004

[21] K. Adachi, S. Iida, K. Hayashi. J. Mater. Res., 9, 1866 (1994).

[22] B. Morten, M. Prudenziati, M. Sacchi, F. Sirotti. J. Appl. Phys., 83, 2267 (1988).

[23] G. Abdurakhmanov. American J. Mater. Sci., 1 (1), 12 (2011). DOI: $10.5923 /$ j.materials.20110101.03

[24] G. Abdurakhmanov, N.G. Abdurakhmanova. Phys. Stat. Sol. (A), 202, 1799 (2005).

[25] H.Y. Fan. Phys. Rev., 78, 808 (1950).

[26] H.Y. Fan. Phys. Rev., 82, 900 (1951).

[27] R. Pässler. Solid-State Electronics, 39, 1311 (1996).

[28] H.D. Vasileff. Phys. Rev., 105, 441 (1957).

[29] K.P. O’Donnell, X. Chen. Appl. Phys. Lett., 58, 2924 (1991).

[30] Л.А. Большов, П.С. Кондратенко, Л.В. Матвеев. УФН 189, 691 (2019).

DOI: https://doi.org/10.3367/UFNr.2018.08. 038423
[31] Н. Мотт, Э. Дэвис. Электронные процессы в некристаллических веществах (Мир, М., 1982), т. 1, с. 16. [Пер. с англ.: N.F. Mott and E.A. Davis. Electron Processes in noncrystalline materials (Clarendon Press, Oxford, 1979)]

[32] A. Feltz. Amorphe und Glasartige Anorganische Festkörper (Akademie-Verlag, Berlin, 1983)

[33] Ф. Либау. Структурная химия силикатов (Мир, М., 1988) [Пер. с англ.: F. Liebau. Structural Chemistry of Silicates (Springer-Verlag, Berlin, 1985)]

[34] Т.А. Сидоров. ЖПС, 6 (1), 98 (1967). 